\title{
Dysregulated expression of claudins in cancer (Review)
}

\author{
JIAN LI \\ Department of General Surgery, The Third Hospital of Mianyang, Sichuan Mental Health Center, \\ Mianyang, Sichuan 621000, P.R. China
}

Received April 1, 2021; Accepted June 14, 2021

DOI: 10.3892/ol.2021.12902

\begin{abstract}
Claudins are adhesion molecules located at the tight junctions between epithelial cells. A series of studies have now reported aberrant expression of claudin proteins in the context of neoplastic transformation, suggesting its role in tumorigenesis. However, the precise mechanisms are still not well understood. Studies on expression alterations of claudins have revealed a range of outcomes that reflect the complexity of claudins in terms of spatial localization, tumor type and stage of disease. The diverse and dynamic expression patterns of claudins in cancer are tightly controlled by a wide range of regulatory mechanisms, which are commonly modulated by oncogenic signaling pathways. The present review summarizes the recent knowledge describing the dysregulation of claudin expression in cancer and discusses the intrinsic and extrinsic determinants of the context-specific expression patterns of claudins.
\end{abstract}

\section{Contents}

1. Introduction

2. TJs and claudins

3. Physiological functions of claudins

4. Expression patterns of claudins

5. Regulation of claudin expression in cancer

6. Future perspectives and conclusions

\section{Introduction}

In 1998, claudins were identified as the major integral membrane proteins essential for tight junction (TJ) assembly (1). Since then, 27 members of this gene family have been found in mammals. Our contemporary understanding of

Correspondence to: $\mathrm{Dr} \mathrm{Jian} \mathrm{Li}$, Department of General Surgery, The Third Hospital of Mianyang, Sichuan Mental Health Center, 190 East Section of Jiannan Road, Youxian, Mianyang, Sichuan 621000, P.R. China

E-mail: 654747973@qq.com

Key words: claudins, cancer, expression, regulation claudins is based on their canonical barrier and fence functions. Recently, this view has expanded considerably following increasing evidence suggesting that claudins may be involved in signal transduction and that they may be causally important in tumorigenesis (2). Obvious dysregulation of claudin expression has been found in a number of cancer tissues. Owing to the specific expression profile and differences between normal and tumor cells, claudins are attractive targets that can theoretically enable selective drug delivery with minimal adverse events (3). To effectively target claudins for clinical applications, it is essential to understand their roles and fully elucidate the complicated mechanisms by which the expression of claudins is dysregulated in cancer. The present study reviews the current knowledge describing the dysregulation of claudin expression in cancer and discusses the intrinsic and extrinsic determinants of the context-specific expression patterns of claudins.

\section{TJs and claudins}

Epithelial and endothelial cells in most living systems form a sheet-like structural interface between the external environment and internal compartments that not only protects the internal organs, but also acts as a selective barrier between the body and the external environment that restricts free exchange across the paracellular space (4). The paracellular space between neighboring cells in the epithelial sheet is connected by several types of cell-cell junctions, which can be categorized as TJs, adherens junctions (AJs) and desmosomes (Fig. 1) (5). AJs bind with the cytoskeleton to impart support and serve as signaling hubs, playing important roles in regulating gene expression (6). Desmosomes create a strong structural network that binds cells together, but is not continuous and cannot prevent solute transport (7). Therefore, TJs are the chief intercellular junctions that act as permeability barriers and confer polarity to epithelial cells in close proximity to adjacent plasma membranes containing $\mathrm{TJ}$ strands formed by TJ proteins (8). TJ proteins are diverse and can be divided into three groups: Transmembrane proteins, adaptor proteins and signaling proteins associated with TJs (9). These proteins interact with each other and other proteins to form a multimeric protein architecture. As key proteins, claudins are a family of integral membrane proteins that are essential for TJ strand assembly.

Claudin (which means 'to close', named after the Latin word 'claudere') was identified as the major integral 
membrane protein forming TJ strands by Tsukita in 1998 (1). A total of 27 homologous claudin genes have been identified in mammals, and numerous more claudin proteins are selectively expressed by alternative splicing in various tissues. According to homology, claudins 1-10, 14, 15, 17 and 19 are homologous classic claudins, while claudins with less homology (claudins 11-13, 16, 18 and 20-27) are non-classical claudins (10). Based on their functions, claudins can also be classified as paracellular barrier-forming claudins function in intracellular space sealing, and paracellular channel-forming claudins function in selective permeability. The paracellular barrier-forming group includes claudins 1, 3-5, 7, 11, 14 and 18, which are responsible for restricting transport and enhancing the barrier function of the cell. The claudins involved in paracellular channel-forming ensure proper availability of water and ions for cellular functions; for example, claudins 10a and 17 allow transport of anions, claudins $10 \mathrm{~b}$ and 15 allow passage of cations, and claudin-2 allows transport of both anions and water (11). The structure of claudins includes four transmembrane domains, the intracellular $\mathrm{N}$ and $\mathrm{C}$ termini, and two extracellular loops (ECLs) (ECL1 and ECL2) (Fig. 1). ECLs are involved in the formation of interactions between claudin strands and determine the characteristics of claudin-based TJs, as their homology is low among claudins (12). ECLs are also specific binding sites for Clostridium perfringens enterotoxin and monoclonal antibodies, which have been utilized for imaging and therapy in pathological conditions (9).

\section{Physiological functions of claudins}

Our contemporary understanding of claudins is based on their canonical barrier and fence functions, which work on the basis of forming TJ complexes. Based on the crystallographic structure of claudin-15 and cysteine cross-linking experiments with mutated claudin-15 and claudin-2, as well as freeze-fracture electron microscopy images, Suzuki et al (13) proposed a model of paracellular pores in which $\beta$-barrel-like channels are formed by the apposition of two anti-parallel double rows of claudins in the membrane of two adjacent cells. Given the results of the crystallization of some other claudins (claudins 3, 4 and 19), this structure seems to be common to other claudins, with differences in residues of their extracellular regions accounting for their different permeabilities and selectivities (14-16). According to physiological studies, two mechanisms have been proposed for paracellular permeability: The 'pore' mechanism, in which solutes or ions pass through a paracellular channel formed by the TJ strands (enabling transport of molecules with an estimated diameter of $~ 4$ Angstrom), and the 'leak' mechanism, in which solutes supposedly pass through breaks in the TJ strands (permitting permeation of molecules up to a size limit of 20 Angstrom) (17). Claudins are also essential for the asymmetric localization of membrane proteins and lipids in the exoplasmic leaflet, acting as a membrane fence in epithelial cells (18).

Our understanding of claudins has expanded considerably over decades of research, following increasing evidence suggesting that claudins may be involved in signal transduction. As the PDZ domain-binding motif located in the cytoplasmic C-terminal tail of claudins can directly interact with zonula occluden (ZO) family proteins, which play important roles in a number of cellular processes, it is not unexpected that claudins participate in signal transduction (9). Claudins mainly function as inhibitory factors through interaction with numerous other signaling pathway elements (such as yes-associated protein/transcriptional co-activator with PDZ-binding motif and $\beta$-catenin), retaining them in the submembrane compartment $(19,20)$. On the other hand, a number of signaling pathways can modify claudins to regulate their protein localization, protein interactions and overall turnover (2). Moreover, mounting evidence suggests that claudins are localized to sites outside the TJ complex, such as the basolateral membrane and nucleus (21). Little is known about the functions of these claudins, and available data support a cell-extracellular matrix interaction and signaling function that integrates, codifies and transports information into the cell (21). These functions are mainly achieved through the formation of a complex between claudins and other molecules, such as integrins, epithelial cell adhesion molecules and matrix metalloproteinases, which leads to the activation of signal transduction (Fig. 2) (22-24).

In line with their aforementioned important functions, dysregulation of claudin-mediated barrier function and signaling is a precursor for the pathogenesis of numerous human diseases, including a number of cancer types (9). For example, mutations of CLDN1, CLDN5, CLDN14, CLDN16, and $C L D N 19$ have been reported to cause human neonatal ichthyosis, sclerosing cholangitis, non-syndromic deafness, familial hypomagnesaemia and other symptoms (9). Knockout of CLDN18 leads to increased abundance and proliferation of known distal lung progenitors, the alveolar epithelial type II (AT2) cells, activation of Yes-associated protein (YAP), and tumorigenesis in mice (20). The dysregulated expression of claudins in cancer has attracted attention, given the increased burden of cancer worldwide.

\section{Expression patterns of claudins}

The claudin expression profile of numerous different tissues and cells, including normal and tumor tissues, has been assessed at the mRNA and protein levels. Studies have revealed a range of outcomes that reflect the complexity of claudins in terms of spatial localization, tumor type and stage of disease. Through a comprehensive review of the transcription data in The Cancer Genome Atlas (TCGA), using the online tool GEPIA (http://gepia.cancer-pku.cn) (Fig. 3), the protein expression data in the Human Protein Atlas (https://www.proteinatlas. org) and individual studies, most of the claudins, if not all, have been reported to show the following expression features.

First, the protein level of claudins is not necessarily correlated with the mRNA level. Although 26 claudin genes have been found in humans (CLDN13 is absent), not each one has been validated at the protein level. Currently, only claudins 1-7, 10-12, 15, 16, 18, 19 and 23 have been identified at the mass spectrometry level, although claudins 8 and 9 have been identified at the protein level by immunoblotting, and some claudins may be expressed in tissues that have not been probed (25). Of them, claudins 1, 3, 4, 6, 7 and 18 are the most extensively studied in tumors.

Second, claudin transcripts can be alternatively spliced to produce isoforms, and some of these isoforms are only found in cancer. Alternatively spliced transcript variants have been 
A
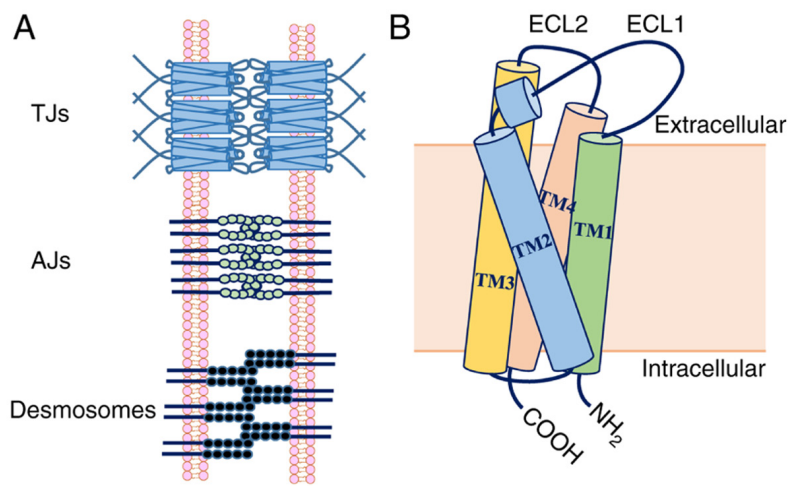

Figure 1. Representative structures of cell-cell junctions and a claudin. (A) The paracellular space between neighboring cells in the epithelial sheet is connected by several types of cell-cell junctions, which can be categorized as TJs, AJs and desmosomes. (B) Claudins are tetratransmembrane proteins, including four transmembrane domains (TM1-4) and two ECLs (ECL1 and ECL2). TJ, tight junction; AJ, adherens junction; ECL, extracellular loop.

found for the majority of $C L D N$ family members, although the protein forms of some of these isoforms have not been detected. Currently, credible immunological evidence exists for the presence of the claudin 10 and 18 protein isoforms claudins $10 \mathrm{a}$ and $10 \mathrm{~b}$ and claudins 18.1 and 18.2 , respectively (26-28). In addition to splice variants that result from differing physiological conditions, many more transcript variants that do not exist in normal tissues may result from alterations that affect RNA splicing, which dysregulate the expression of CLDN genes, contributing to cancer progression (29).

Third, the expression of claudins changes dynamically during development and differentiation. Claudin- 6 expression was reported to be 90 -fold higher in undifferentiated human pluripotent stem cells than in differentiated cells, while in adult tissues, it was nearly completely absent $(30,31)$. The expression of claudin-1 declines with differentiation, whereas the expression of claudin- 4 increases and is highest in the late stage, in which human embryonic stem cells transition into hepatocyte-like cells (32). In the colon, claudin-7 expression gradually increases with the differentiation of epithelial cells into luminal cells, which results in an expression gradient from the basal side to the surface of the intestinal lumen (33). Age-related changes in expression have also been reported, including changes in claudin-3 expression, which is downregulated with aging (34).

Fourth, although various claudins are expressed in the same tissue simultaneously, distinct claudin members are expressed in a tissue-specific manner. Claudins 18 and 19 are two typical examples. Claudin-18 expression is restricted to the lung, where it is present as the isoform claudin-18.1, and to the stomach, where it is present as the isoform claudin-18.2 (27). Claudin-19 is detected mainly in the thick ascending limb of the loop of Henle, the retinal epithelium and peripheral neurons in normal tissues (35). The expression of claudins 1,4 and 7 is relatively widespread and closely related to cancer $(36,37)$. Single-site specificity within one organ was also discovered for claudin-1 expression, as claudin-1 mRNA expression was found to be higher in the distal site than in the proximal site of the colon (38).

Fifth, the expression of claudins appears to be reversed with carcinogenesis; that is, a claudin that is downregulated in a specific tissue will be upregulated in tumors arising from that tissue, while a claudin that is upregulated in a specific tissue will be expressed at low levels in tumors derived from that tissue. This is especially true for claudin-18 and -6 . In one study, the expression of claudin-18 nearly disappeared in lung cancer tissues and was significantly downregulated in gastric cancer tissues, while it was ectopically upregulated in pancreatic cancer tissues (27). Claudin-6 is a strictly oncofetal cell surface antigen whose expression is tightly regulated and completely absent in normal human tissues, but reactivated in germline tumors such as testicular, ovarian and uterine cancer (31).

Sixth, the expression levels of some claudins are heterogeneous within tumors and may differ in different cancer subtypes. For example, in estrogen receptor (ER)-positive luminal A and luminal B breast cancer, the expression of claudin-1 was found to be downregulated, while in the ER-negative basal-like breast cancer subtype, increased expression and cytoplasmic delocalization were observed (39). Consensus molecular subtype 2 and the transit-amplifying and C5 subtypes of metastatic colorectal cancer exhibit higher expression of claudin-1 than other subtypes (40). The expression levels of claudins are also not homogeneous intratumorally. Claudin-1 expression was shown to be retained in the central regions, but lost in the invasive edges in colorectal cancer (CRC) tissues (41). Although the majority of studies have agreed with these findings, some studies have reported the opposite results, especially for claudins that are widely expressed in a number of cancer types (claudins 1, 4 and 7) (36,37).

Seventh, changes in the expression of claudins are a very early event, although these changes are always exacerbated with the progression of the cancer. Claudin-1 was shown to be upregulated in the course of colitis, while claudin-7 mRNA levels were decreased in adenomas, suggesting that changes in claudin-7 mRNA levels are an early event in the development of CRC $(42,43)$. Claudin-18 mRNA levels were also found to be decreased in intestinal metaplasia and intraepithelial neoplasia tissues before gastric cancer formation, but were commonly increased in precursor lesions of pancreatic cancer $(27,44)$.

\section{Regulation of claudin expression in cancer}

Since the expression patterns of claudins are diverse and dynamic, the transcription and function of claudins must be tightly controlled via a wide range of regulatory mechanisms, including genetic background, epigenetic alterations, transcriptional changes and post-translational modifications (PTMs), which are commonly modulated by oncogenic signaling pathways. Extrinsic factors, including the cancer cell of origin, differentiation status, pre-existing or acquired tumor microenvironment and environmental factors, also determine the expression profile of claudins (Table I; Fig. 4).

Genetic background. Currently, cancer is regarded as a disease characterized by uncontrolled cellular growth caused primarily by genetic alterations, which mainly occur in a set of cancer driver genes, conferring transformed cells with certain selective advantages over neighboring cells (45). Although no claudin gene mutations were identified as drivers in any tumor type in an analysis using the IntOGen platform, genetic 


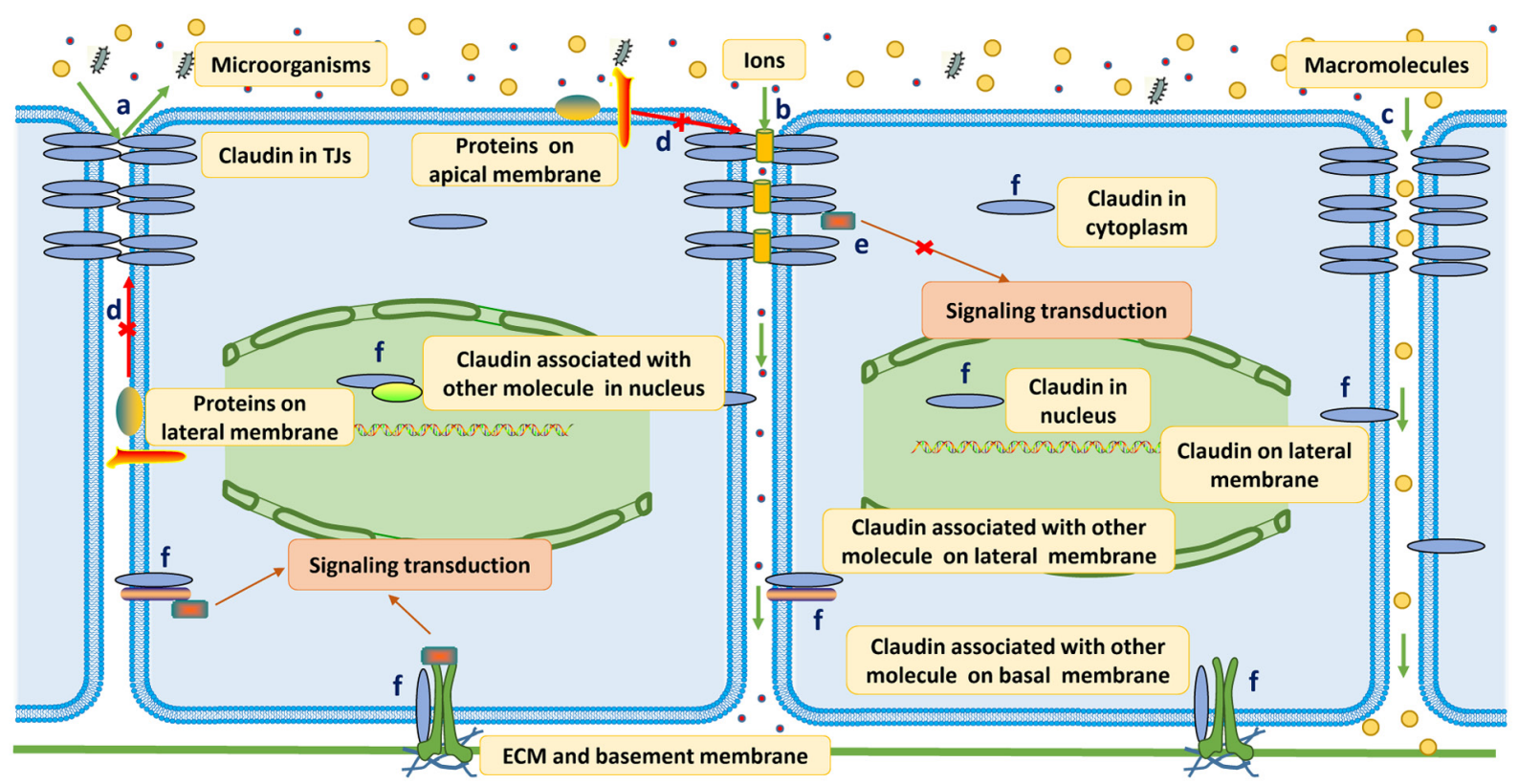

Figure 2. Physiological functions of claudins. a, TJ assembly: Close apposition of adjacent plasma membranes where TJ strands are formed by claudins. b, The 'pore' pathway: Solutes or ions pass through a paracellular channel determined by the charged residue status in the first ECL (ECL1) of claudins. c, The 'leak' pathway, in which solutes supposedly pass through the paracellular space, dependent on the breaking and reorganization of claudin strands. d, Fence function: Proteins and lipids in the exoplasmic leaflet cannot freely diffuse across claudin strands. e, Signaling transduction: Claudins mainly function as inhibitory factors and retain signaling molecules in the submembrane compartment. f, Claudins outside TJs always associate with other molecules to engage in cell-ECM interactions and signal transduction. TJ, tight junction; ECM, extracellular matrix; ECL, extraceullar loop.

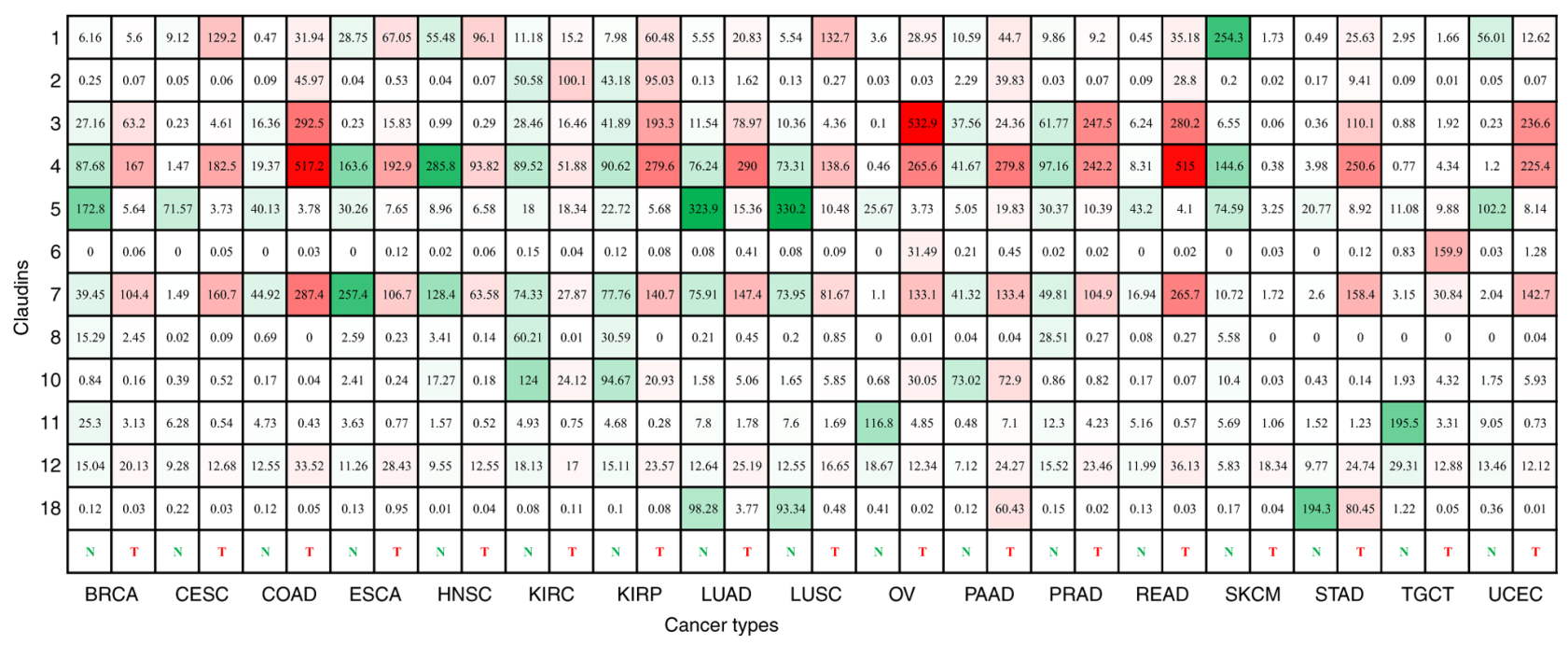

Figure 3. Expression of claudin genes in human cancer. The figure shows the expression of claudin genes in various common cancer types and subtypes. The green color corresponds to normal tissues, and the red color corresponds to tumor tissues. The depth of color represents the strength of expression. The numbers in each box are the median transcripts per million of certain tumor and normal tissues. This figure was compiled using data generated by The Cancer Genome Atlas and Genotype-Tissue Expression projects, accessible through GEPIA. BRCA, invasive breast carcinoma; CESC, cervical squamous carcinoma; COAD, colon adenocarcinoma; ESCA, esophageal carcinoma; HNSC, head and neck squamous cell carcinoma; KIRC, kidney renal clear cell carcinoma; KIRP, kidney renal papillary cell carcinoma; LUAD, lung adenocarcinoma; LUSC, lung squamous carcinoma; OV, ovarian serous cystadenocarcinoma; PAAD, pancreatic adenocarcinoma; PRAD, prostate adenocarcinoma; READ, rectum adenocarcinoma; SKCM, skin cutaneous melanoma; STAD, stomach adenocarcinoma; TGCT, testicular germ cell tumor; UCEC, uterine corpus endometrial carcinoma; N, normal tissues; T, tumor tissues.

alteration patterns can be informed from sequencing data from a number of large tumor sequencing initiatives, such as TCGA $(46,47)$. In the present review, cBioPortal was searched using TCGA PanCancer Atlas data (https://www.cbioportal. org/) and the frequencies and types of genetic alterations of CLDNs in cancer were found to vary depending on the tumor and $C L D N$ type, and an important degree of variability across cancer subtypes (histological and molecular) was also observed. Some genetic alterations occur across several cancer types, while others tend to be more specific. Therefore, the differences in the expression of claudins in cancer may result from this genetic heterogeneity. Two examples are the expression patterns of claudin- 1 and -6 , which are always overexpressed in squamous cancer types and ovarian cancer, 
Table I. Regulation of claudin expression in cancer. ${ }^{\mathrm{a}}$

Type of claudin regulation

Regulator Cancer type

Mechanism

Function

(Refs.)

\begin{tabular}{|c|c|c|c|}
\hline \multirow[t]{2}{*}{ Genetic } & Amplification & SCC & Amplification $\rightarrow$ claudin-1 increased \\
\hline & & Ovarian cancer & Amplification $\rightarrow$ claudin- 6 increased \\
\hline \multirow[t]{2}{*}{ Epigenetic } & $\begin{array}{l}\text { DNA } \\
\text { methylation }\end{array}$ & Breast cancer & $\begin{array}{l}\text { DOCK } 1 \rightarrow \text { RRP1B } \rightarrow \text { DNMT } \rightarrow \text { claudin- } \\
\text { decreased }\end{array}$ \\
\hline & $\begin{array}{l}\text { Histone } \\
\text { modifications }\end{array}$ & $\mathrm{HCC}$ & $\begin{array}{l}\mathrm{EZH} 2 \rightarrow \mathrm{H} 3 \mathrm{~K} 27 \mathrm{ME} 3 \text { increased } \rightarrow \\
\text { claudin-14 decreased } \rightarrow \text { Wnt } / \beta \text {-catenin } \\
\text { signaling activity increased }\end{array}$ \\
\hline \multirow{13}{*}{$\begin{array}{l}\text { Signaling } \\
\text { pathways and } \\
\text { TFs }\end{array}$} & $\begin{array}{l}\text { ERK, } \\
\text { Akt and/or }\end{array}$ & Breast cancer & $\begin{array}{l}\text { ADAM } 15 \rightarrow \mathrm{PI} 3 \mathrm{~K} / \mathrm{Akt} / \mathrm{mTOR} \\
\text { increased } \rightarrow \text { claudin- } 1 \text { increased }\end{array}$ \\
\hline & $\beta$-catenin & Lung cancer & $\begin{array}{l}\mathrm{PI} 3 \mathrm{~K} / \mathrm{Akt} / \mathrm{NF}-\kappa \mathrm{B} \rightarrow \text { claudin- } 1 \\
\text { increased }\end{array}$ \\
\hline & & $\begin{array}{l}\text { Cervical } \\
\text { cancer }\end{array}$ & $\begin{array}{l}\text { Estrogen } \rightarrow \text { GPR } 30 \rightarrow \text { ERK and/or } \\
\text { Akt increased } \rightarrow \text { claudin- } 1 \text { increased }\end{array}$ \\
\hline & & $\begin{array}{l}\text { Pancreatic } \\
\text { cancer } \\
\text { CRC }\end{array}$ & $\begin{array}{l}\text { PKC } \alpha \rightarrow \text { Snail and MAPK/ERK } \\
\text { increased } \rightarrow \text { claudin- } 1 \text { decreased } \\
\beta \text {-catenin } \rightarrow \text { claudin-7 decreased }\end{array}$ \\
\hline & TGF- $\beta / S$ & Lung cancer & TGF- $\beta \rightarrow$ Smad $\rightarrow$ claudin- 4 \\
\hline & MAD & & increased \\
\hline & JAK/STAT & $\mathrm{HCC}$ & $\begin{array}{l}\text { hGH } \rightarrow \text { STAT3 } \rightarrow \text { claudin }-1 \\
\text { decreased }\end{array}$ \\
\hline & EMT-TFs & $\mathrm{SCC}$ & Snail $\rightarrow$ claudin-11 increased \\
\hline & & $\begin{array}{l}\text { Pancreatic } \\
\text { cancer }\end{array}$ & $\begin{array}{l}\text { ZIP4 } \rightarrow \text { ZEB } 1 \rightarrow \text { claudin- } 1 \text { decreased } \rightarrow \\
\text { FAK and Paxill increased }\end{array}$ \\
\hline & Others & $\begin{array}{l}\text { Gastric } \\
\text { cancer }\end{array}$ & RUNX3 $\rightarrow$ claudin-1 increased \\
\hline & & $\begin{array}{l}\text { Prostate } \\
\text { cancer }\end{array}$ & $\mathrm{AR} \rightarrow$ claudin- 8 increased \\
\hline & & $\begin{array}{l}\text { Gastric } \\
\text { cancer }\end{array}$ & $\begin{array}{l}\text { NSAIDs } \rightarrow \text { intracellular } \mathrm{Ca} 2+ \\
\text { increased } \rightarrow \text { claudin- } 4 \text { increased }\end{array}$ \\
\hline & & Lung cancer & $\begin{array}{l}\text { TNF- } \alpha \rightarrow \text { PKC } / \text { iPLA } 2 / \text { PGE2/PPAR } \gamma \\
\text { increased } \rightarrow \text { claudin-1 increased }\end{array}$ \\
\hline \multirow[t]{6}{*}{$\begin{array}{l}\text { mRNA } \\
\text { stability }\end{array}$} & miRs & $\mathrm{CRC}$ & $\begin{array}{l}\text { miR- } 488 \rightarrow \text { claudin- } 2 \text { decreased } \rightarrow \\
\text { MAPK decreased }\end{array}$ \\
\hline & & $\mathrm{HCC}$ & miR-486 $\rightarrow$ claudin-10 decreased \\
\hline & & Gastric cancer & $\begin{array}{l}\text { miR-146-5p } \rightarrow \text { claudin-12 } \\
\text { decreased } \rightarrow \text { Wnt/ } \beta \text {-catenin and } \\
\mathrm{PI} 3 \mathrm{~K} / \mathrm{AKT} / \mathrm{MAPK} \text { increased } \\
\text { miR-1303 } \rightarrow \text { claudin-18 decreased }\end{array}$ \\
\hline & LncRNA & Colon cancer & $\begin{array}{l}\text { LINC00662 } \rightarrow \text { miR-340-5p } \\
\text { decreased } \rightarrow \text { claudin-8/IL22/ERK } \\
\text { increased }\end{array}$ \\
\hline & & Gastric cancer & $\begin{array}{l}\text { LncRNA PCAT } 18 \rightarrow \text { miR-135b } \\
\text { decreased } \rightarrow \text { claudin-11 increased }\end{array}$ \\
\hline & Others & Colon cancer & $\begin{array}{l}\text { HDACs } \rightarrow 3 \text { '-UTR } \rightarrow \text { claudin-1 } \\
\text { increased }\end{array}$ \\
\hline
\end{tabular}

Cellustering

increased

Anticancer drugs

penetration decreased

Survival, proliferation,

migration and invasion

increased

EMT increased

increased

Motility, invasive

EMT increased

Motility and

tumorigenicity increased

Invasive and CSC-like

properties increased

Collective cell migration

and invasion increased

Migration and invasion

increased

Tumorigenicity

decreased

Proliferation and

migration increased

Anchorage-independent

growth and cell migration

decreased

Morphology changes and

migration increased

Cell proliferation,

EMT, and lymph node metastasis decreased

Growth, colony formation and migration decreased Cell viability, migration and invasion increased; apoptosis decreased Proliferation, migration and invasion increased Proliferation, invasion and migration increased; apoptosis decreased Proliferation, migration and invasion decreased dedifferentiation and invasion increased 
Table I. Continued.

Type of claudin regulation

Regulator Cancer type

Mechanism

Function

(Refs.)

\begin{tabular}{|c|c|c|c|c|}
\hline \multirow[t]{4}{*}{ PTMs } & Phospharylation & $\mathrm{SCC}$ & $\begin{array}{l}\text { Claudin- } 11 \text { tyrosine phosphorylation } \rightarrow \\
\text { Src increased } \rightarrow \text { p } 190 \text { RhoGAP } \\
\text { increased } \rightarrow \text { RhoA activity } \\
\text { decreased } \rightarrow \text { stable cell-cell } \\
\text { contacts increased }\end{array}$ & $\begin{array}{l}\text { Collective cell migration } \\
\text { and invasion increased }\end{array}$ \\
\hline & & $\mathrm{RCC}$ & $\begin{array}{l}\text { EphA2/Ephrin A } 1 \rightarrow \text { claudin- } 4 \text { tyrosine } \\
\text { phosphorylation increased } \rightarrow \\
\text { cytoplasmic translocation increased; } \\
\text { PKC- } \varepsilon \rightarrow \text { claudin- } 4 \text { serine } \\
\text { phosphorylation increased }+\mathrm{YAP} \rightarrow \\
\text { nuclear translocation increased }\end{array}$ & EMT increased \\
\hline & Palmitoylation & $\mathrm{RCC}$ & $\begin{array}{l}\text { Palmitoylated claudin- } \rightarrow \text { GEM } \rightarrow \text { integrin } \\
\text { and EpCAM recruitment } \\
\text { increased } \rightarrow \text { cytoskeletal } \\
\text { linker proteins and MMP14, } \\
\text { CD147 and TACE association } \\
\text { increased }\end{array}$ & $\begin{array}{l}\text { Motility, matrix } \\
\text { degradation and EpCAM } \\
\text { cleavage increased }\end{array}$ \\
\hline & & $\begin{array}{l}\text { Ovarian } \\
\text { cancer }\end{array}$ & $\begin{array}{l}\text { ZDHHC12 } \rightarrow \text { claudin- } 3 \text { palmitoylation } \\
\text { increased } \rightarrow \text { accurate plasma membrane } \\
\text { localization and protein stability increased }\end{array}$ & $\begin{array}{l}\text { Tumorigenic promotion } \\
\text { effect increased }\end{array}$ \\
\hline
\end{tabular}

${ }^{a}$ The table is not an exhaustive list and is used only to highlight the relevance of claudins in numerous cancer types. ADAM, a disintegrin and metalloproteinase; AR, androgen receptor; CRC, colorectal cancer; CSC, cancer stem cell; DNMT, DNA methyltransferases; DOCK, dedicator of cytokinesis; EMT, epithelial-mesenchymal transition; EpCAM, epithelial cell adhesion molecule; EphA, ephrin type-A receptors; ERK, extracellular signal-regulated kinase; EZH, enhancer of zeste homolog; FAK, focal adhesion kinase; GEM, glycolipid-enriched membrane domain; GPR, G-protein-coupled receptor; HCC, hepatocellular carcinoma; HDAC, histone deacetylase; hGH, human growth hormone; IL, interleukin; iPLA, calcium-independent phospholipase A; JAK, Janus kinase; lncRNA, long non-coding RNA; MAPK, mitogen-activated protein kinase; miR, microRNA; MMP, matrix metalloproteinase; NSAID, non-steroidal anti-inflammatory drug; NF- $\kappa \mathrm{B}$, nuclear factor- $\mathrm{kB}$; PGE, prostaglandin; PKC, protein kinase C; PPAR, peroxisome proliferator-activated receptor; PTM, post-translational modification; RCC, renal cell carcinoma; RhoGAP, Rho GTPase activating protein; RRP1B, ribosomal RNA processing 1B; SCC, squamous cell carcinoma; STAT, signal transducer and activator of transcription; TACE, TNF- $\alpha$ converting enzyme; TF, transcription factor; TGF- $\beta$, transforming growth factor- $\beta$; UTR, untranslated region; YAP, yes-associated protein; ZEB, zinc finger E-box binding homeobox; ZDHHC12, zinc finger DHHC-type palmitoyltransferase 12; ZIP, Zrt-/Irt-like protein.

respectively, consistent with the high amplification rates of the two genes in these cancer types $(31,48)$. However, in a number of cases, the impact of amplification on the expression of an individual gene is relatively subtle, and the common deep deletion of CLDN20-25 has not been validated at the protein level. Therefore, except for genetic alterations, the expression of claudins in cancer is regulated by other factors.

Epigenetic alterations. At the epigenetic level, at least some members of the claudin family are subjected to extensive epigenetic regulation. The context-specific differences in chromatin organization and DNA accessibility may direct the level of claudins in cancer (49). For example, promoter hypomethylation and histone $\mathrm{H} 3$ hyperacetylation of $C L D N 3$ were shown to increase claudin-3 expression in ovarian cancer cells, while DNA hypermethylation of the promoter of $C L D N 1$ was an important factor for the low expression of claudin-1 in ER-positive breast cancer $(50,51)$. In breast cancer cells with low claudin expression, dedicator of cytokinesis 1 mediates the downregulation of claudin-1 expression through promoter activity suppression by DNA methyltransferase, leading to cancer progression and metastasis (52). For some claudins, expression changes with changes in methylation. For example, claudin-18.2 expression decreases as the methylation of $\mathrm{CpG}$ in promoter regions increases in gastric cancer, but increases as methylation decreases in pancreatic cancer (27). Histone modifications such as H3K27ME3, catalyzed by enhancer of zeste homolog 2 , were also demonstrated to decrease the expression of claudin-14, providing an explanation for the aggressive nature of hepatocellular carcinoma (HCC) with downregulation of claudin-14 (53). Epigenetic alterations have a greater impact on cancer cell phenotypes than genomic alterations, and the epigenetic status can be highly plastic, suggesting that epigenetic regulation have a dominant impact on claudin expression, consistent with the diverse and dynamic expression patterns of claudins.

Transcription factors. Expression regulation of claudins is also tightly controlled by different transcription factors 


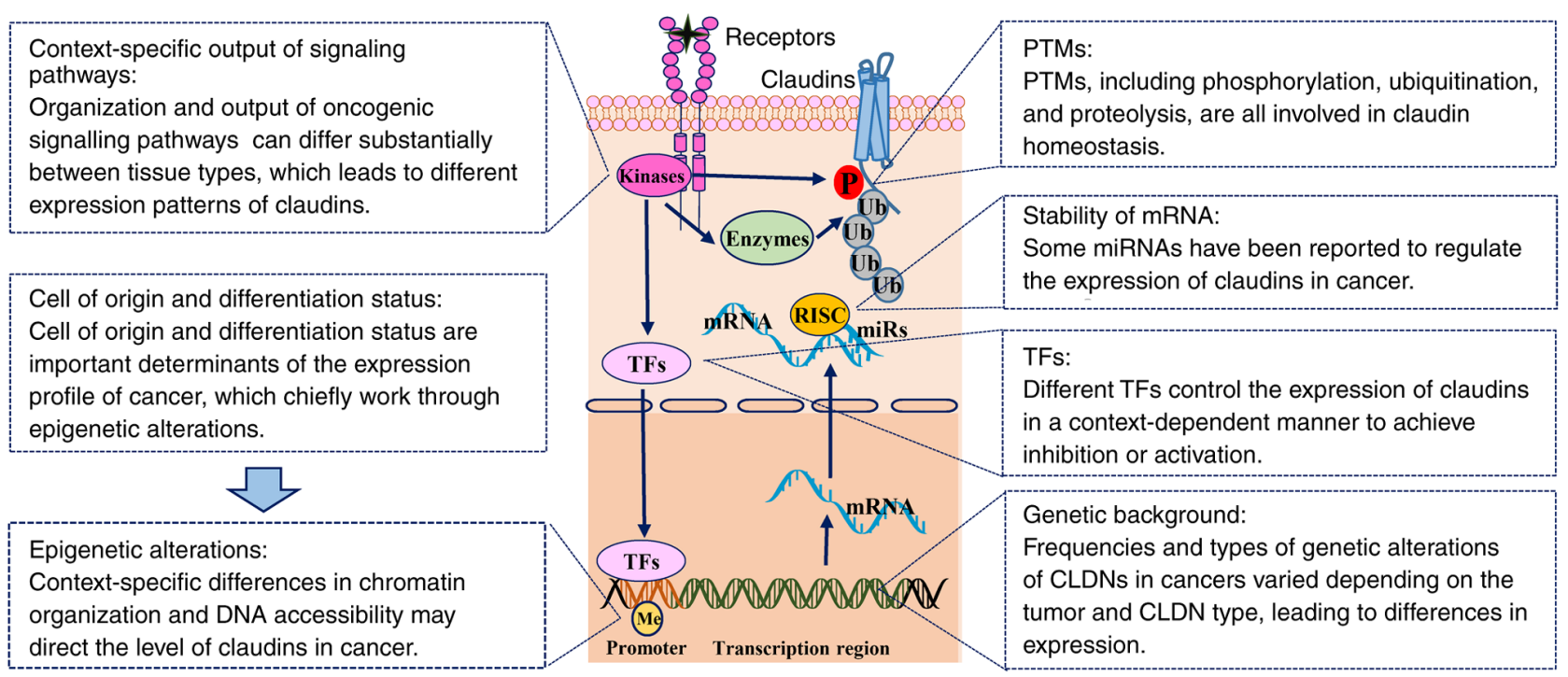

Figure 4. Regulation of claudin expression in cancer. The expression of claudins is tightly controlled via a wide range of regulatory mechanisms, including genetic background, epigenetic alterations, transcriptional changes and PTMs, which are commonly modulated by oncogenic signaling pathways. Extrinsic factors include the cancer cell of origin, differentiation status, pre-existing or acquired tumor microenvironment and environmental factors, which also determine the expression profile of the claudins. CLDN, claudin; Me, methylation; miRNA, microRNA; P, phosphorylation; PTM, post-translational modification; RISC, RNA-induced silencing complex; TF, transcription factor; Ub, ubiquitination.

(TFs). Different TFs control the expression of claudins in a context-dependent manner to achieve inhibition or activation, which reflects the diverse expression patterns of the claudins. Acting at the onset and in the progression of cancer, neoplastic conversion profoundly alters the claudin repertoire in cancer cells to achieve neoplastic transformation. TFs involved in epithelial-mesenchymal transition (EMT) are major drivers of these alterations (54-56). Studies have shown that claudin-1 expression is inhibited by Slug and Snail in breast cancer, but activated by caudal homeobox proteins ( $\mathrm{Cdx} 1$ and $\mathrm{Cdx} 2)$, GATA binding protein 4 and $\beta$-catenin in colon cancer via interactions with different elements in the promoter $(54,55)$. Claudin-7 expression is negatively regulated by Snail by the direct binding of Snail to the E-box of promoter regions, but is positively regulated by embryonic liver fodrin 3 and hepatocyte nuclear factor 4 , whose binding sites are all also located in the promoter region (56-58). Some claudins also exhibit high pairwise sequence homology, so coordinated gene expression is possible, and the same TF can regulate the expression of different claudins simultaneously; for example, Sp1 is known to regulate claudin-3 and -4 promoter activity in ovarian cancer $(50,59,60)$. The effects of TFs on claudin expression are context-dependent; for example, the EMT-TF Snail induces claudin-11 expression and prompts collective migration for tumor progression in squamous cell carcinoma, whereas another EMT-TF, zinc finger E-box binding homeobox 1 (ZEB1), promotes pancreatic cancer progression by repressing claudin-1 expression, reflecting the complexity of the roles of the claudins in cancer development $(61,62)$.

Stability of mRNA. At the mRNA level, alternative or mis-splicing can change the expression levels of claudins. Several mis-splicing variants resulting in a premature stop codon and thus likely leading to nonsense-mediated decay have been found for CLDN1 and CLDN18 $(27,29)$. The stability of mRNA is one of the most important determinants of protein expression. MicroRNAs (miRs/miRNAs) are short non-coding RNAs (ncRNAs) that inhibit the expression of target genes by directly binding to their target mRNAs, and some miRNAs have been reported to regulate the expression of claudins in cancer. For example, miR-146-5p promotes cell viability, migration and invasion, inhibits apoptosis and activates oncogenic pathways by decreasing claudin-2 expression in lung cancer cells, while miR-488 could suppress the cell proliferation, EMT and lymph node metastasis of CRC cells via inhibition of claudin-2 expression $(63,64)$. miR-486 functions as a tumor suppressor in HCC by targeting claudin-10, which decreases cancer cell proliferation, colony formation and migration, while miR-1303 functions as an oncogenic miRNA in gastric cancer. Downregulation of miR-1303 can inhibit proliferation, migration and invasion of cancer cells by targeting claudin-18 $(65,66)$. Another type of ncRNA, long ncRNA, can also affect the expression of claudins through effects on miRNAs, with protumor or antitumor roles in a context-dependent manner $(67,68)$. Furthermore, one study revealed that histone deacetylases (HDACs) modulate claudin-1 mRNA stability by interacting with its 3' untranslated region, indicating the application of HDAC inhibitors in such settings with anticancer promise (69).

PTMs. Apart from these transcriptional regulatory mechanisms, claudin levels and functions are also known to be regulated by PTMs that affect their protein interactions, trafficking, subcellular localization, oligomer assembly and overall turnover (25). Dysregulation of the transportation of claudins, such as the cytoplasmic accumulation of claudin-1 induced by inhibition of endosomal sorting complexes required for transport, causes TJs to disassemble and lose cell polarity (70). PTMs, including phosphorylation, palmitoylation, ubiquitination, glycosylation and proteolysis, are all involved in claudin homeostasis (25). 
Almost all signaling pathways involved in cancer contain kinases; therefore, it is not surprising that the phosphorylation of claudins is an important PTM that affects their localization and function. In addition, some data have demonstrated that claudin delocalization contributes to cancer hallmarks. For instance, activated ephrin receptor A2 phosphorylates the tyrosine residue of claudin-4, decreasing its association with ZO-1 and leading to claudin-4 accumulation in the cytoplasm, which decreases the integration of claudin-4 into TJs. Further phosphorylation of the serine residue by protein kinase $\mathrm{C}$ (PKC) results in nuclear import of claudin-4 (71,72). By contrast, tyrosine phosphorylation of claudin-11 activates Src to maintain stable cell-cell contacts by suppressing RhoA activity, which prompts the formation of circulating tumor cell clusters (61). Palmitoylation of claudin-7 affects the relative amounts of claudin-7 in the basolateral membrane by leading to the incorporation of claudin-7 into glycolipid-enriched membrane domains and inhibiting its integration into TJs, while palmitoylation of claudin-3 by zinc finger DHHC-type palmitoyltransferase 12 contributes to plasma membrane localization, protein stability and ovarian cancer cell tumorigenesis $(73,74)$. Although evidence from humans is scarce, ubiquitination and protease cleavage of claudins have been observed in human cells under normal physiological or inflammatory conditions, but their roles in cancer need further research (75-77).

Cell of origin and differentiation status. The cell of origin and differentiation status are important determinants of the expression profile of cancer, which is shaped during the development of the cancer, although alterations always occur to some extent after malignant transformation. For example, claudin-1 is especially crucial for squamous epithelium such as the skin, whose germline mutations mainly cause neonatal ichthyosis. Therefore, the expression of claudin-1 is high in squamous cancer types, whereas cancer types with adenocarcinomatous components are likely to lose claudin-1 expression (48). Another example is claudin-6, which is an oncofetal cell surface antigen that is completely silenced in normal human tissues, but reactivated in germline cancers such as testicular, ovarian and uterine cancer (31). Another mechanism contributing to the different expression profiles of claudins in cancer is the differentiation status of cancer cells. Key studies have shown that some cancer types display a hierarchical nature founded by a cancer stem cell or a malignant cell that has gained stem cell properties, leading to reversal of the differentiation signals put in place during development and acquisition of characteristics of the undifferentiated state (78). In this regard, this phenomenon may explain the dysregulated expression of claudins in some cancer types. For example, claudin-2 expression is restricted to the stem/progenitor cell compartment in the normal intestinal epithelium; however, claudin-2 is widely expressed in human CRC tissues $(79,80)$. By contrast, the expression of claudin-18.2 is absent from the stem cell zone of gastric glands, but increased in differentiated gastric cells. When gastric cancer arises from these stem cells or the cells transition into an undifferentiated state, the expression of claudin-18.2 significantly decreases (81).

Context-specific output of signaling pathways. In the majority of instances, oncogene activation lies upstream of most protein expression dysregulation in cancer cells. However, different cell and tissue types show profound differences in their response to oncogenic driver mutations, and the organization and output of oncogenic signaling pathways, such as MAPK, PI3K/Akt, WNT/ $\beta$-catenin and NF- $\kappa \mathrm{B}$ signalling, can differ substantially between tissue types, which leads to different expression patterns of claudins (82-95). For example, in lung cancer cells, claudin-1 is upregulated through activation of the PI3K/Akt/NF- $\kappa \mathrm{B}$ pathway, while in pancreatic cancer cells, claudin-1 is downregulated by $\mathrm{PKC} \alpha$ via Snail- and MAPK/ERK-dependent pathways $(82,83)$. Moreover, the membrane zinc importer Zrt-/Irt-like protein 4 (ZIP4) was found to be overexpressed in human pancreatic, and it was demonstrated that ZIP4 represses claudin-1 through a ZEB1-dependent transcriptional mechanism (84). The contradictory roles of claudin-1 in different cancer types reflect the fact that different oncogenic pathways can hijack different roles of claudins to contribute to cancer progression. In addition, signaling pathways also encode, process and integrate external and internal signals, providing a specific and appropriate response to external stimuli. Therefore, the expression of claudins is further complicated by the output of these signals integrated from external stimuli, such as spatial and temporal variability in nutrients, oxygenation, growth factors and hormones. For example, estrogen/GPR30 signaling induces claudin-1 expression in ER-negative cervical adenocarcinoma (85). Glucose was found to regulate the expression of claudin-2 in endometrial cancer (86). Additionally, some vitamins can regulate the expression of claudins. For example, vitamin D can regulate claudin-2 and -4 protein levels (87).

\section{Future perspectives and conclusions}

Consistent with the diversity of claudin expression in cancer, numerous studies on the roles of claudins in carcinogenesis have reported contradictory results. However, the data suggest that even if it does not function as a cancer driver, claudin dysregulation assists in the initiation and progression of cancer and is involved in nearly all aspects of tumor biology and all steps of tumor development. In addition to their various roles in cancer, from a translational perspective, as classic cell surface molecules, claudins may be ideal targets for therapy. As aforementioned, claudin expression has tissue specificity and is dysregulated in cancer. Furthermore, it has been observed that most claudins are buried in the TJ complex in normal tissues, while higher accessibility is caused by extrajunctional mislocalization in malignant tissues (96). Owing to this specific expression profile and difference between normal and tumor cells, claudin-targeting strategies seem to hold substantial promise, and this idea has been validated by clinical applications using specific claudin-targeting therapies (targeting claudin-6 and -18.2) (97). For the majority of claudins, with the exception of claudin- 6 and -18.2 , although the antitumor effect has been verified in proof-of-concept experiments, they remain at the laboratory stage, and their translation into clinical practice is eagerly awaited.

Overall, the dysregulated expression of claudins is a common phenotype associated with a number of different cancer types. The tissue-, cancer- and stage-specific expression patterns of claudins are the result of the regulation of various 
factors at different levels, from genetic background to tumor microenvironment alterations. Along with the understanding of the dysregulation of claudin expression in cancer, the exploration of their role in tumorigenesis and thus in cancer treatment and prevention will be advanced.

\section{Acknowledgements}

Not applicable.

\section{Funding}

No funding was received.

\section{Availability of data and materials}

The datasets generated and analyzed during the current study are available in TCGA repository and cBioPortal.

\section{Authors' contributions}

JL conceived the paper, wrote the initial draft, generated the figures, edited and revised the original manuscript, and read and approved the final manuscript. Data authentication is not applicable.

\section{Ethics approval and consent to participate}

Not applicable.

\section{Patient consent for publication}

Not applicable.

\section{Competing interests}

The author declares that they have no competing interests.

\section{References}

1. Furuse M, Sasaki H, Fujimoto K and Tsukita S: A single gene product, claudin-1 or -2 , reconstitutes tight junction strands and recruits occludin in fibroblasts. J Cell Biol 143: 391-401, 1998.

2. Singh AB, Uppada SB and Dhawan P: Claudin proteins, outside-in signaling, and carcinogenesis. Pflugers Arch 469: 69-75, 2017.

3. Hashimoto Y, Tachibana K, Krug SM, Kunisawa J, Fromm M and Kondoh M: Potential for tight junction protein-Directed drug development using claudin binders and angubindin-1. Int J Mol Sci 20: 4016, 2019.

4. Schneeberger EE and Lynch RD: The tight junction: A multifunctional complex. Am J Physiol Cell Physiol 286: C1213-C1228, 2004.

5. Niessen CM: Tight junctions/adherens junctions: Basic structure and function. J Invest Dermatol 127: 2525-2532, 2007.

6. Meng W and Takeichi M: Adherens junction: Molecular architecture and regulation. Cold Spring Harb Perspect Biol 1: a002899, 2009.

7. Kottke MD, Delva E and Kowalczyk AP: The desmosome: Cell science lessons from human diseases. J Cell Sci 119 (Pt 5): 797-806, 2006.

8. Farquhar MG and Palade GE: Junctional complexes in various epithelia. J Cell Biol 17: 375-412, 1963.

9. Zihni C, Mills C, Matter K and Balda MS: Tight junctions: From simple barriers to multifunctional molecular gates. Nat Rev Mol Cell Biol 17: 564-580, 2016.
10. Lal-Nag M and Morin PJ: The claudins. Genome Biol 10: 235 , 2009.

11. Tsukita S, Tanaka H and Tamura A: The Claudins: From tight junctions to biological systems. Trends Biochem Sci 44: 141-152, 2019.

12. Suzuki H, Nishizawa T, Tani K, Yamazaki Y, Tamura A, Ishitani R, Dohmae N, Tsukita S, Nureki O and Fujiyoshi Y: Crystal structure of a claudin provides insight into the architecture of tight junctions. Science 344: 304-307, 2014.

13. Suzuki H, Tani K, Tamura A, Tsukita S and Fujiyoshi Y: Model for the architecture of claudin-based paracellular ion channels through tight junctions. J Mol Biol 427: 291-297, 2015.

14. Saitoh Y, Suzuki H, Tani K, Nishikawa K, Irie K, Ogura Y, Tamura A, Tsukita S and Fujiyoshi Y: Tight junctions. Structural insight into tight junction disassembly by Clostridium perfringens enterotoxin. Science 347: 775-778, 2015.

15. Shinoda T, Shinya N, Ito K, Ohsawa N, Terada T, Hirata K, Kawano Y, Yamamoto M, Kimura-Someya T, Yokoyama S and Shirouzu M: Structural basis for disruption of claudin assembly in tight junctions by an enterotoxin. Sci Rep 6: 33632, 2016.

16. Nakamura S, Irie K, Tanaka H, Nishikawa K, Suzuki H, Saitoh Y, Tamura A, Tsukita S and Fujiyoshi Y: Morphologic determinant of tight junctions revealed by claudin-3 structures. Nat Commun 10: 816, 2019.

17. Shen L, Weber CR, Raleigh DR, Yu D and Turner JR: Tight junction pore and leak pathways: A dynamic duo. Annu Rev Physiol 73: 283-309, 2011

18. Otani $\mathrm{T}$ and Furuse M: Tight junction structure and function revisited. Trends Cell Biol 30: 805-817, 2020.

19. Ahmad R, Kumar B, Chen Z, Chen X, Müller D, Lele SM, Washington MK, Batra SK, Dhawan P and Singh AB: Loss of claudin-3 expression induces IL6/gp130/Stat3 signaling to promote colon cancer malignancy by hyperactivating Wnt/ $\beta$-catenin signaling. Oncogene 36: 6592-6604, 2017.

20. Zhou B, Flodby P, Luo J, Castillo DR, Liu Y, Yu FX, McConnell A, Varghese B, Li G, Chimge NO, et al: Claudin-18-mediated YAP activity regulates lung stem and progenitor cell homeostasis and tumorigenesis. J Clin Invest 128: 970-984, 2018.

21. Hagen SJ: Non-canonical functions of claudin proteins: Beyond the regulation of cell-cell adhesions. Tissue Barriers 5: e1327839, 2017.

22. Lu Z, Kim DH, Fan J, Lu Q, Verbanac K, Ding L, Renegar R and Chen YH: A non-tight junction function of claudin-7-Interaction with integrin signaling in suppressing lung cancer cell proliferation and detachment. Mol Cancer 14: 120, 2015.

23. Nübel T, Preobraschenski J, Tuncay H, Weiss T, Kuhn S, Ladwein M, Langbein L and Zöller M: Claudin-7 regulates EpCAM-mediated functions in tumor progression. Mol Cancer Res 7: 285-299, 2009.

24. Pope JL, Bhat AA, Sharma A, Ahmad R, Krishnan M, Washington MK, Beauchamp RD, Singh AB and Dhawan P: Claudin-1 regulates intestinal epithelial homeostasis through the modulation of Notch-signalling. Gut 63: 622-634, 2014.

25. Liu F, Koval M, Ranganathan S, Fanayan S, Hancock WS, Lundberg EK, Beavis RC, Lane L, Duek P, McQuade L, et al: Systems proteomics view of the endogenous human claudin protein family. J Proteome Res 15: 339-359, 2016.

26. Milatz S and Breiderhoff T: One gene, two paracellular ion channels-claudin-10 in the kidney. Pflugers Arch 469: 115-121, 2017.

27. Li J, Zhang Y, Hu D, Gong T, Xu R and Gao J: Analysis of the expression and genetic alteration of CLDN18 in gastric cancer. Aging (Albany NY) 12: 14271-14284, 2020.

28. Milatz S: A novel claudinopathy based on claudin-10 mutations. Int J Mol Sci 20: 5396, 2019.

29. Blanchard AA, Zelinski T, Xie J, Cooper S, Penner C, Leygue E and Myal Y: Identification of claudin 1 transcript variants in human invasive breast cancer. PLoS One 11: e0163387, 2016

30. Ben-David U, Nudel $\mathrm{N}$ and Benvenisty $\mathrm{N}$ : Immunologic and chemical targeting of the tight-junction protein Claudin- 6 eliminates tumorigenic human pluripotent stem cells. Nat Commun 4: 1992, 2013

31. Reinhard K, Rengstl B, Oehm P, Michel K, Billmeier A, Hayduk N, Klein O, Kuna K, Ouchan Y, Wöll S, et al: An RNA vaccine drives expansion and efficacy of claudin-CAR-T cells against solid tumors. Science 367: 446-453, 2020.

32. Erdélyi-Belle B, Török G, Apáti Á, Sarkadi B, Schaff Z, Kiss A and Homolya L: Expression of tight junction components in hepatocyte-like cells differentiated from human embryonic stem cells. Pathol Oncol Res 21: 1059-1070, 2015. 
33. Fujita H, Chiba H, Yokozaki H, Sakai N, Sugimoto K, Wada T, Kojima T, Yamashita T and Sawada N: Differential expression and subcellular localization of claudin-7, $-8,-12,-13$, and -15 along the mouse intestine. J Histochem Cytochem 54: 933-944, 2006.

34. D'Souza T, Sherman-Baust CA, Poosala S, Mullin JM and Morin PJ: Age-related changes of claudin expression in mouse liver, kidney, and pancreas. J Gerontol A Biol Sci Med Sci 64: $1146-1153,2009$

35. Perdomo-Ramirez A, Aguirre M, Davitaia T, Ariceta G, Ramos-Trujillo E; RenalTube Group and Claverie-Martin F: Characterization of two novel mutations in the claudin-16 and claudin-19 genes that cause familial hypomagnesemia with hypercalciuria and nephrocalcinosis. Gene 689: 227-234, 2019.

36. Ouban A: Claudin-1 role in colon cancer: An update and a review. Histol Histopathol 33: 1013-1019, 2018.

37. Wang $\mathrm{K}, \mathrm{Xu} \mathrm{C}, \mathrm{Li} \mathrm{W}$ and Ding L: Emerging clinical significance of claudin-7 in colorectal cancer: A review. Cancer Manag Res 10: 3741-3752, 2018.

38. Dhawan P, Singh AB, Deane NG, No Y, Shiou SR, Schmidt C, Neff J, Washington MK and Beauchamp RD: Claudin-1 regulates cellular transformation and metastatic behavior in colon cancer. J Clin Invest 115: 1765-1776, 2005.

39. Blanchard AA, Skliris GP, Watson PH, Murphy LC, Penner C, Tomes L, Young TL, Leygue E and Myal Y: Claudins 1, 3, and 4 protein expression in ER negative breast cancer correlates with markers of the basal phenotype. Virchows Arch 454: 647-656, 2009

40. Cherradi S, Ayrolles-Torro A, Vezzo-Vié N, Gueguinou N, Denis V,CombesE, BoissièreF, Busson M,Canterel-Thouennon L, Mollevi C, et al: Antibody targeting of claudin-1 as a potential colorectal cancer therapy. J Exp Clin Cancer Res 36: 89, 2017.

41. Matsuoka T, Mitomi H, Fukui N, Kanazawa H, Saito T, Hayashi T and Yao T: Cluster analysis of claudin-1 and -4, E-cadherin, and $\beta$-catenin expression in colorectal cancers. J Surg Oncol 103 674-686, 2011

42. Bhat AA, Ahmad R, Uppada SB, Singh AB and Dhawan P: Claudin-1 promotes TNF- $\alpha$-induced epithelial-mesenchymal transition and migration in colorectal adenocarcinoma cells Exp Cell Res 349: 119-127, 2016

43. Bornholdt J, Friis S, Godiksen S, Poulsen SS, Santoni-Rugiu E, Bisgaard HC, Lothe IM, Ikdahl T, Tveit KM, Johnson E, et al: The level of claudin-7 is reduced as an early event in colorectal carcinogenesis. BMC Cancer 11: 65, 2011.

44. Tanaka M, Shibahara J, Fukushima N, Shinozaki A, Umeda M, Ishikawa S, Kokudo $\mathrm{N}$ and Fukayama M: Claudin-18 is an early-stage marker of pancreatic carcinogenesis. J Histochem Cytochem 59: 942-952,2011.

45. Stratton MR: Exploring the genomes of cancer cells: Progress and promise. Science 331: 1553-1558, 2011

46. Gonzalez-Perez A, Perez-Llamas C, Deu-Pons J, Tamborero D, Schroeder MP, Jene-Sanz A, Santos A and Lopez-Bigas N IntOGen-mutations identifies cancer drivers across tumor types. Nat Methods 10: 1081-1082, 2013

47. Martínez-Jiménez F, Muiños F, Sentís I, Deu-Pons J, Reyes-Salazar I, Arnedo-Pac C, Mularoni L, Pich O, Bonet J, Kranas $\mathrm{H}$, et al: A compendium of mutational cancer driver genes. Nat Rev Cancer 20: 555-572, 2020.

48. Paschoud S, Bongiovanni M, Pache JC and Citi S: Claudin-1 and claudin-5 expression patterns differentiate lung squamous cell carcinomas from adenocarcinomas. Mod Pathol 20: 947-954, 2007.

49. Schaefer MH and Serrano L: Cell type-specific properties and environment shape tissue specificity of cancer genes. Sci Rep 6: 20707, 2016

50. Honda H, Pazin MJ, D'Souza T, Ji H and Morin PJ: Regulation of the CLDN3 gene in ovarian cancer cells. Cancer Biol Ther 6 : $1733-1742,2007$.

51. Di Cello F, Cope L, Li H, Jeschke J, Wang W, Baylin SB and Zahnow CA: Methylation of the claudin 1 promoter is associated with loss of expression in estrogen receptor positive breast cancer. PLoS One 8: e68630, 2013.

52. Chiang SK, Chang WC, Chen SE and Chang LC: DOCK1 regulates growth and motility through the RRP1B-claudin-1 pathway in claudin-low breast cancer cells. Cancers (Basel) 11: 1762, 2019.

53. Li CP, Cai MY, Jiang LJ, Mai SJ, Chen JW, Wang FW, Liao YJ, Chen WH, Jin XH, Pei XQ, et al: CLDN14 is epigenetically silenced by EZH2-mediated H3K27ME3 and is a novel prognostic biomarker in hepatocellular carcinoma. Carcinogenesis 37 : 557-566, 2016
54. Martínez-Estrada OM, Cullerés A, Soriano FX, Peinado H, Bolós V, Martínez FO, Reina M, Cano A, Fabre M and Vilaró S: The transcription factors Slug and Snail act as repressors of Claudin-1 expression in epithelial cells. Biochem J 394(Pt 2): 449-457, 2006.

55. Bhat AA, Sharma A, Pope J, Krishnan M, Washington MK, Singh AB and Dhawan P: Caudal homeobox protein Cdx-2 cooperates with Wnt pathway to regulate claudin-1 expression in colon cancer cells. PLoS One 7: e37174, 2012

56. Feng J, Cen J, Li J, Zhao R, Zhu C, Wang Z, Xie J and Tang W: Histone deacetylase inhibitor valproic acid (VPA) promotes the epithelial mesenchymal transition of colorectal cancer cells via up regulation of Snail. Cell Adh Migr 9: 495-501, 2015.

57. Kohno Y, Okamoto T, Ishibe T, Nagayama S, Shima Y, Nishijo K, Shibata KR, Fukiage K, Otsuka S, Uejima D, et al: Expression of claudin7 is tightly associated with epithelial structures in synovial sarcomas and regulated by an Ets family transcription factor, ELF3. J Biol Chem 281: 38941-38950, 2006.

58. Farkas AE, Hilgarth RS, Capaldo CT, Gerner-Smidt C, Powell DR, Vertino PM, Koval M, Parkos CA and Nusrat A: HNF4alpha regulates claudin-7 protein expression during intestinal epithelial differentiation. Am J Pathol 185: 2206-2218, 2015.

59. Baltzegar DA, Reading BJ, Brune ES and Borski RJ: Phylogenetic revision of the claudin gene family. Mar Genomics 11: 17-26, 2013.

60. Honda H, Pazin MJ, Ji H, Wernyj RP and Morin PJ: Crucial roles of $\mathrm{Sp} 1$ and epigenetic modifications in the regulation of the CLDN4 promoter in ovarian cancer cells. J Biol Chem 281: 21433-21444, 2006.

61. Li CF, Chen JY, Ho YH, Hsu WH, Wu LC, Lan HY, Hsu DS, Tai SK, Chang YC and Yang MH: Snail-induced claudin-11 prompts collective migration for tumour progression. Nat Cell Biol 21: 251-262, 2019.

62. Liu M, Yang J, Zhang Y, Zhou Z, Cui X, Zhang L, Fung KM, Zheng W, Allard FD, Yee EU, et al: ZIP4 promotes pancreatic cancer progression by repressing ZO-1 and claudin-1 through a ZEB1-dependent transcriptional mechanism. Clin Cancer Res 24: 3186-3196, 2018.

63. Sun X, Cui S, Fu X, Liu C, Wang Z and Liu Y: MicroRNA-146-5p promotes proliferation, migration and invasion in lung cancer cells by targeting claudin-12. Cancer Biomark 25: 89-99, 2019.

64. Wang YB, Shi Q,Li G,Zheng JH,Lin J and Qiu W: MicroRNA-488 inhibits progression of colorectal cancer via inhibition of the mitogen-activated protein kinase pathway by targeting claudin- 2 . Am J Physiol Cell Physiol 316: C33-C47, 2019.

65. Sun H, Cui C, Xiao F, Wang H, Xu J, Shi X, Yang Y, Zhang Q, Zheng X, Yang X, et al: MiR-486 regulates metastasis and chemosensitivity in hepatocellular carcinoma by targeting CLDN10 and CITRON. Hepatol Res 45: 1312-1322, 2015.

66. Zhang SJ, Feng JF, Wang L, Guo W, Du YW, Ming L and Zhao GQ: MiR-1303 targets claudin-18 gene to modulate proliferation and invasion of gastric cancer cells. Dig Dis Sci 59: 1754-1763, 2014.

67. Cheng B, Rong A, Zhou Q and Li W: LncRNA LINC00662 promotes colon cancer tumor growth and metastasis by competitively binding with miR-340-5p to regulate CLDN8/IL22 co-expression and activating ERK signaling pathway. J Exp Clin Cancer Res 39: 5, 2020.

68. Zhang XZ, Mao HL, Zhang SJ, Sun L, Zhang WJ, Chen QZ, Wang L and Liu HC: 1ncRNA PCAT18 inhibits proliferation, migration and invasion of gastric cancer cells through miR-135b suppression to promote CLDN11 expression. Life Sci 249: 117478,2020

69. Krishnan M, Singh AB, Smith JJ, Sharma A, Chen X, Eschrich S, Yeatman TJ, Beauchamp RD and Dhawan P: HDAC inhibitors regulate claudin-1 expression in colon cancer cells through modulation of mRNA stability. Oncogene 29: 305-312, 2010.

70. Zhou B, Moodie A, Blanchard AA, Leygue E and Myal Y: Claudin 1 in breast cancer: New insights. J Clin Med 4: 1960-1976, 2015

71. Tanaka M, Kamata R and Sakai R: EphA2 phosphorylates the cytoplasmic tail of Claudin-4 and mediates paracellular permeability. J Biol Chem 280: 42375-42382, 2005.

72. Owari T, Sasaki T, Fujii K, Fujiwara-Tani R, Kishi S, Mori S, Mori T, Goto K, Kawahara I, Nakai Y, et al: Role of nuclear claudin-4 in renal cell carcinoma. Int J Mol Sci 21: 8340, 2020.

73. Heiler S, Mu W, Zöller M and Thuma F: The importance of claudin-7 palmitoylation on membrane subdomain localization and metastasis-promoting activities. Cell Commun Signal 13: 29, 2015 . 
74. Yuan M, Chen X, Sun Y, Jiang L, Xia Z, Ye K, Jiang H, Yang B, Ying M, Cao J and He Q: ZDHHC12-mediated claudin-3 $\mathrm{S}$-palmitoylation determines ovarian cancer progression. Acta Pharm Sin B 10: 1426-1439, 2020.

75. Mandel I, Paperna T, Volkowich A, Merhav M, Glass-Marmor L and Miller A: The ubiquitin-proteasome pathway regulates claudin 5 degradation. J Cell Biochem 113: 2415-2423, 2012.

76. Gong Y, Wang J, Yang J, Gonzales E, Perez R and Hou J: KLHL3 regulates paracellular chloride transport in the kidney by ubiquitination of claudin-8. Proc Natl Acad Sci USA 112: 4340-4345, 2015

77. Willemsen LE, Hoetjes JP, van Deventer SJ and van Tol EA Abrogation of IFN-gamma mediated epithelial barrier disruption by serine protease inhibition. Clin Exp Immunol 142: 275-284, 2005.

78. Lytle NK, Barber AG and Reya T: Stem cell fate in cancer growth, progression and therapy resistance. Nat Rev Cancer 18: 669-680, 2018

79. Rahner C, Mitic LL and Anderson JM: Heterogeneity in expression and subcellular localization of claudins $2,3,4$, and 5 in the rat liver, pancreas, and gut. Gastroenterology 120: 411-422, 2001

80. Paquet-Fifield S, Koh SL, Cheng L, Beyit LM, Shembrey C, Mølck C, Behrenbruch C, Papin M, Gironella M, Guelfi S, et al: Tight junction protein claudin-2 promotes self-renewal of human colorectal cancer stem-like cells. Cancer Res 78: 2925-2938, 2018

81. Sahin U, Koslowski M, Dhaene K, Usener D, Brandenburg G, Seitz G, Huber C and Türeci O: Claudin-18 splice variant 2 is a pan-cancer target suitable for therapeutic antibody development. Clin Cancer Res 14: 7624-7634, 2008.

82. Akizuki R, Maruhashi R, Eguchi H, Kitabatake K, Tsukimoto M, Furuta T, Matsunaga T, Endo S and Ikari A: Decrease in paracellular permeability and chemosensitivity to doxorubicin by claudin-1 in spheroid culture models of human lung adenocarcinoma A549 cells. Biochim Biophys Acta Mol Cell Res 1865: 769-780, 2018.

83. Kyuno D, Kojima T, Yamaguchi H, Ito T, Kimura Y, Imamura M, Takasawa A, Murata M, Tanaka S, Hirata K and Sawada N: Protein kinase $\mathrm{C} \alpha$ inhibitor protects against downregulation of claudin-1 during epithelial-mesenchymal transition of pancreatic cancer. Carcinogenesis 34: 1232-1243, 2013.

84. Li M, Zhang Y, Liu Z, Bharadwaj U, Wang H, Wang X, Zhang S, Liuzzi JP, Chang SM, Cousins RJ, et al: Aberrant expression of zinc transporter ZIP4 (SLC39A4) significantly contributes to human pancreatic cancer pathogenesis and progression. Proc Natl Acad Sci USA 104: 18636-18641, 2007.

85. Akimoto T, Takasawa A, Takasawa K, Aoyama T, Murata M, Osanai M, Saito T and Sawada N: Estrogen/GPR30 signaling contributes to the malignant potentials of ER-negative cervical adenocarcinoma via regulation of claudin-1 expression. Neoplasia 20: 1083-1093, 2018.

86. Okada T, Konno T, Kohno T, Shimada H, Saito K, Satohisa S, Saito $\mathrm{T}$ and Kojima T: Possibility of targeting claudin-2 in therapy for human endometrioid endometrial carcinoma. Reprod Sci 27: 2092-2103, 2020.
87. Domazetovic V, Iantomasi T, Bonanomi AG and Stio M: Vitamin $D$ regulates claudin-2 and claudin-4 expression in active ulcerative colitis by $\mathrm{p}$-Stat- 6 and Smad-7 signaling. Int J Colorectal Dis 35: 1231-1242, 2020.

88. Mattern J, Roghi CS, Hurtz M, Knäuper V, Edwards DR and Poghosyan Z: ADAM15 mediates upregulation of claudin-1 expression in breast cancer cells. Sci Rep 9: 12540, 2019.

89. Kim WK, Kwon Y, Jang M, Park M, Kim J, Cho S, Jang DG, Lee WB, Jung $\mathrm{SH}$, Choi $\mathrm{HJ}$, et al: $\beta$-catenin activation down-regulates cell-cell junction-related genes and induces epithelial-to-mesenchymal transition in colorectal cancers. Sci Rep 9: 18440, 2019.

90. Rachakonda G, Vu T, Jin L, Samanta D and Datta PK: Role of TGF- $\beta$-induced Claudin- 4 expression through c-Jun signaling in non-small cell lung cancer. Cell Signal 28: 1537-1544, 2016

91. Chen YJ, You ML, Chong QY, Pandey V, Zhuang QS, Liu DX, Ma L, Zhu T and Lobie PE: Autocrine human growth hormone promotes invasive and cancer stem cell-like behavior of hepatocellular carcinoma cells by STAT3 dependent inhibition of CLAUDIN-1 expression. Int J Mol Sci 18: 1274, 2017.

92. Chang TL, Ito K, Ko TK, Liu Q, Salto-Tellez M, Yeoh KG, Fukamachi $\mathrm{H}$ and Ito Y: Claudin-1 has tumor suppressive activity and is a direct target of RUNX3 in gastric epithelial cells. Gastroenterology 138: 255-265.e1-3, 2010.

93. Ashikari D, Takayama KI, Obinata D, Takahashi S and Inoue S: CLDN8, an androgen-regulated gene, promotes prostate cancer cell proliferation and migration. Cancer Sci 108: 1386-1393, 2017.

94. Mima S, Tsutsumi S, Ushijima H, Takeda M, Fukuda I, Yokomizo K, Suzuki K, Sano K, Nakanishi T, Tomisato W, et al: Induction of claudin-4 by nonsteroidal anti-inflammatory drugs and its contribution to their chemopreventive effect. Cancer Res 65: 1868-1876, 2005.

95. Iitaka D, Moodley S, Shimizu H, Bai XH and Liu M: PKC 8 -iPLA2-PGE2-PPAR $\gamma$ signaling cascade mediates TNF- $\alpha$ induced Claudin 1 expression in human lung carcinoma cells. Cell Signal 27: 568-577, 2015

96. Morin PJ: Claudin proteins in human cancer: Promising new targets for diagnosis and therapy. Cancer Res 65: 9603-9606, 2005.

97. Singh P, Toom S and Huang Y: Anti-claudin 18.2 antibody as new targeted therapy for advanced gastric cancer. J Hematol Oncol 10: 105, 2017

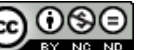

This work is licensed under a Creative Commons Attribution-NonCommercial-NoDerivatives 4.0 International (CC BY-NC-ND 4.0) License. 